
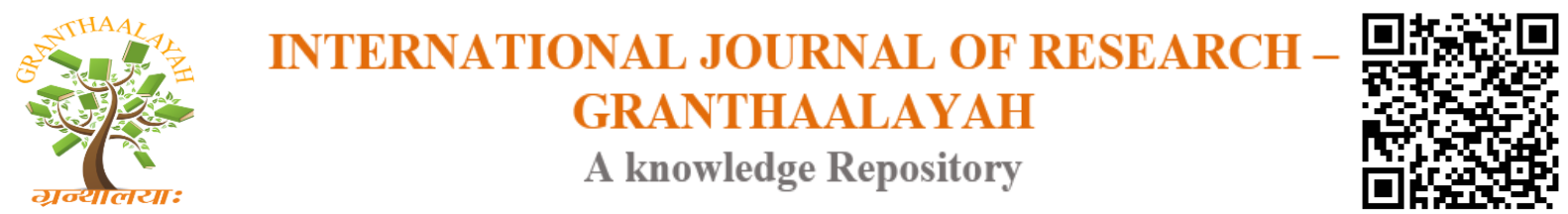

Science

\title{
EXTENDED THEORETICAL CONCEPT OF COMPLEX FUZZY SETS BY COMPLEX FUZZY SOFT HYPERGROUP, COMPLEX FUZZY SOFT HYPERRING
}

\author{
P. Thirunavukarasu ${ }^{1}$, V. Ashokkumar ${ }^{2}$, R. Suresh $^{3}$, W. Lilly Merline ${ }^{4}$ \\ ${ }^{1,4}$ Asst. Prof -P.G \& Research Department of Mathematics, Periyar E.V.R College \\ (Autonomous), Tiruchirappalli - 620 023, TamilNadu, INDIA \\ ${ }^{2}$ Associate Professor, Mathematics Section, Shinas College of Technology, SULTANATE OF \\ OMAN \\ ${ }^{3}$ Asst. Prof -Department of Mathematics, Kings College of Engineering, Punalkulam, \\ Pudukkottai (Dist.) - 613 303, TamilNadu, INDIA
}

DOI: https://doi.org/10.29121/granthaalayah.v4.i7(SE).2016.2629

\begin{abstract}
In this paper, we develop the initial theory of complex fuzzy soft hypergroup by introducing the novel concept of complex fuzzy soft hypergroup, complex fuzzy soft hyperring. Consequently, a major part of this work is dedicated to extend the theory of complex fuzzy soft set, complex fuzzy hypergroup. Complex fuzzy soft quasihypergroup, complex fuzzy soft semihypergroup and complex fuzzy soft subhypergroup also discussed in this paper.
\end{abstract}

Keywords:

complex fuzzy set, complex fuzzy soft set, complex fuzzy soft hypergroup, complex fuzzy soft hyperring.

Cite This Article: P. Thirunavukarasu, V.Ashokkumar, R. Suresh, and W. Lilly Merline, "EXTENDED THEORETICAL CONCEPT OF COMPLEX FUZZY SETS BY COMPLEX FUZZY SOFT HYPERGROUP, COMPLEX FUZZY SOFT HYPERRING”, International Journal of Research - Granthaalayah, Vol. 4, No. 7: SE (2016): 62-69.

\section{INTRODUCTION}

Soft set theory is a generalization of fuzzy set theory, which was proposed by Molodtsov [10] in 1999 to deal with uncertainty in a non-parametric manner. One of the most important steps for the theory of Soft Sets was to define mappings on soft sets, this was achieved in 2009 by mathematician Athar Kharal, though the results were published in 2011. Soft sets, soft intuitionistic fuzzy set [9] have also been applied to the problem of medical diagnosis for use in medical expert systems. Fuzzy soft sets have also been introduced in [8]. Mappings on fuzzy soft sets[2,9] were defined and studied in the ground breaking work of Kharal and Ahmad. 
Complex fuzzy set (CFS) [11]-[12] is a new development in the theory of fuzzy systems [14]. The concept of CFS is an extension of fuzzy set, by which the membership for each element of a complex fuzzy set is extended to complex-valued state. Complex fuzzy hyperstructure [1], complex fuzzy hypergroup [1] is also a latest development in the theory of complex fuzzy set.

This paper is organized as follows: Section 2 reviews the concept of complex fuzzy hypergroup based on complex fuzzy set on complex fuzzy spaces. In section 3 , we reviews the complex fuzzy soft set ,complex fuzzy soft hypergroup, complex fuzzy soft hyperring based on complex fuzzy soft set. Finally we conclude the paper with a summary in section 4 .

\section{PRELIMINARIES}

Definition 2.1: Ramot et al. [11] recently proposed an important extension of these ideas, the Complex Fuzzy Sets, where the membership function $\mu$ instead of being a real valued function with the range $[0,1]$ is replaced by a complex-valued function of the form

$$
\mu_{s}(x)=r_{s}(x) e^{j \omega_{s}(x)} ; \mathrm{j}=\sqrt{-1}
$$

where $r_{S}(x)$ and $\omega_{S}(x)$ are both real valued giving the range as the unit circle. However, this concept is different from fuzzy complex number introduced and discussed by Buckley and Zhang. Essentially as explained in [11] this still retains the characterization of the uncertainty through the amplitude of the grade of membership having a value in the range of $[0,1]$ whilst adding the membership phase captured by fuzzy sets. As explained in Ramot et al [11], the key feature of complex fuzzy sets is the presence of phase and its membership.

Definition 2.2: [1]Let $\mathrm{E}^{2}$ be the unit disc. Then the Cartesian product $\mathrm{E}^{2} \mathrm{xE}^{2}$ with partial order defined by:

$$
\text { (i) }\left(r_{1} e^{i \omega_{\eta}}, r_{2} e^{i \omega_{r 2}}\right) \leq\left(s_{1} e^{i \omega_{s 1}}, s_{2} e^{i \omega_{s 2}}\right) \text { iff } r_{1} \leq s_{1} \text { and } r_{2} \leq s_{2}, \omega_{r 1} \leq \omega_{s 1}, \omega_{r 2} \leq \omega_{s 2}
$$

whenever $\mathrm{s}_{1} \neq 0$ and $\mathrm{s}_{2} \neq 0$ for all $r_{1}, s_{1}, \omega_{r 1}, \omega_{s 1} \in E^{2}$ and $r_{2}, s_{2}, \omega_{r 2}, \omega_{s 2} \in E^{2}$

(ii) $\left(0 e^{i \omega_{n}}, 0 e^{i \omega_{r 2}}\right)=\left(s_{1} e^{i \omega_{s 1}}, s_{2} e^{i \omega_{s 2}}\right)$ whenever, $s_{1}=0$ or $s_{2}=0$ and

$$
\omega_{1}=0 \text { or } \omega_{2}=0 \text { for every } s_{1}, \omega_{1} \in E^{2} \text { and } s_{2}, \omega_{2} \in E^{2} \text {. }
$$

Definition 2.3: [1] A complex fuzzy space, denoted by $\left(X, E^{2}\right)$, where $E^{2}$ is the unit disc, is set of all ordered pairs $\left(\mathrm{x}, \mathrm{E}^{2}\right), \quad \mathrm{x} \in \mathrm{X}$, i.e. $\left(\mathrm{X}, \mathrm{E}^{2}\right)=\left\{\left(x, E^{2}\right): x \in X\right\}$. We can write $\left(x, E^{2}\right)=\left\{\left(x, r e^{i \omega}\right): r e^{i \omega} \in E^{2}\right\}$, where $\mathrm{i}=\sqrt{-1}, r \in[0,1]$, and $\omega \in[0,2 \pi]$.

The ordered pair $\left(x, E^{2}\right)$ is called a complex fuzzy element in the complex fuzzy space $\left(X, E^{2}\right)$. Therefore, the complex fuzzy space is an (ordinary) set of ordered pairs. In each pair the first component indicates the (ordinary) element and the second component indicates a set of possible complex membership values $\left(r e^{i \omega}\right.$, where $\mathrm{r}$ represents an amplitude term and $\omega$ represents a phase term).

Definition 2.4: [1] Let $\left(H, \mathrm{E}^{2}\right)$ be a non-empty complex fuzzy space. A complex fuzzy hyperstructure (hypergroupoid), denoted by $\left(\left(H, E^{2}\right) ; \diamond\right)$ is a complex fuzzy space together with a complex fuzzy function having onto co-membership functions(referred as a complex fuzzy 
hyperoperation) $\diamond:\left(H, E^{2}\right) X\left(H, E^{2}\right) \rightarrow \mathrm{P}^{*}\left(\left(H, E^{2}\right)\right)$, where $\mathrm{P}^{*}\left(\mathrm{H}, \mathrm{E}^{2}\right)$ denotes the set of all nonempty complex fuzzy subspaces of $\left(\mathrm{H}, \mathrm{E}^{2}\right)$ and $\diamond=\left(\Delta, \nabla_{x y}\right)$ with $\Delta: H \times H \rightarrow P^{*}(H)$ and $\nabla_{x y}: E^{2} \times E^{2} \rightarrow E^{2}$ for all $x, y \in H$.

Definition: 2.5: [1] A complex fuzzy hypergroup is a complex fuzzy hyperstructure $<\left(H, E^{2}\right) ; \diamond>$ satisfying the following axioms:

(i) $\left.\left(\left(x, E^{2}\right) \oslash\left(y, E^{2}\right)\right) \diamond\left(z, E^{2}\right)=\left(x, E^{2}\right) \diamond\left(\left(y, E^{2}\right)\right) \diamond\left(z, E^{2}\right)\right)$

for all $\left(x, E^{2}\right),\left(y, E^{2}\right),\left(z, E^{2}\right) \in\left(H, E^{2}\right)$,

(ii) $\left.\left(x, E^{2}\right) \oslash\left(H, E^{2}\right)=\left(H, E^{2}\right) \oslash\left(x, E^{2}\right)=\left(H, E^{2}\right)\right)$ for all $\left(x, E^{2}\right) \in\left(H, E^{2}\right)$.

Definition 2.6: [5] A complex fuzzy $H_{v}$-group is a complex fuzzy hyperstructure $\left\langle\left(H, E^{2}\right) ; \diamond\right\rangle$ satisfying the following conditions:

(i) $\left.\left(\left(x, E^{2}\right) \diamond\left(y, E^{2}\right)\right) \diamond\left(z, E^{2}\right) \bigcap\left(x, E^{2}\right) \diamond\left(\left(y, E^{2}\right)\right) \diamond\left(z, E^{2}\right)\right) \neq \phi$,

for all $\left(x, E^{2}\right),\left(y, E^{2}\right),\left(z, E^{2}\right) \in\left(H, E^{2}\right)$,

(ii) $\left.\left(x, E^{2}\right) \oslash\left(H, E^{2}\right)=\left(H, E^{2}\right) \oslash\left(x, E^{2}\right)=\left(H, E^{2}\right)\right)$ for all $\left(x, E^{2}\right) \in\left(H, E^{2}\right)$.

If $<\left(H, E^{2}\right) ; \diamond>$ satisfies only the first condition of Definition 3.5 then it is called a complex fuzzy semihypergroup (Complex fuzzy $H_{v}$ semigroup)

Definition 2.7: A complex fuzzy hyper group (complex fuzzy $H_{v}$-group) $\left\langle\left(H, E^{2}\right) ; \diamond\right\rangle$ is called a commutative (or abelian) fuzzy hypergroup if $\left.\left(\left(x, E^{2}\right) \diamond\left(y, E^{2}\right)\right)=\left(\left(y, E^{2}\right)\right) \diamond\left(x, E^{2}\right)\right)$ for all for all $\left(x, E^{2}\right),\left(y, E^{2}\right) \in\left(H, E^{2}\right)$.

Definition 2.8: Let $<\left(H, E^{2}\right) ; \diamond>$ be a complex fuzzy hypergroup (complex fuzzy $H_{v}$-group) and let $U=\left\{\left(x, r e^{i \omega_{x}}\right): x \in U_{0}\right\}$ be a complex fuzzy subspace of $\left(H, E^{2}\right)$, then $(U ; \diamond)$ is called a complex fuzzy sub-hypergroup (complex fuzzy $H_{v}$-subgroup) of the complex fuzzy hypergroup $<\left(H, E^{2}\right) ; \diamond>$ if $\diamond$ is closed on the complex fuzzy subspace $U$ and $(U ; \diamond)$ satisfies the conditions of a complex fuzzy hypergroup (Complex fuzzy $H_{v}$-group)

\section{COMPLEX FUZZY SOFT HYPERGROUP}

In this section, the concept of complex fuzzy soft set and complex fuzzy soft hypergroup are studied.

Definition 3.1: $[3,13]$ Let $U$ be an initial set, $E$ be set of parameters and $C(U)$ denotes complex fuzzy power set of $U$, and let $A \subseteq E$. A pair $(C, A)$ is called a complex fuzzy soft set over $U$, where $\mathrm{C}$ is a mapping given by $\mathrm{C}: \mathrm{A} \rightarrow \mathrm{C}(\mathrm{U})$. 
Definition 3.2: [7,13] The complement of a complex fuzzy soft set $(\mathrm{C}, \mathrm{A})$ is denoted by $(\mathrm{C}, \mathrm{A})^{\mathrm{c}}$ and is defined by $(\mathrm{C}, \mathrm{A})^{\mathrm{c}}=\left(\mathrm{C}^{\mathrm{c}}, \neg \mathrm{A}\right)$, where $\mathrm{C}^{\mathrm{c}}: \neg \mathrm{A} \rightarrow \mathrm{C}(\mathrm{U})$ is a mapping given by $\mathrm{C}^{\mathrm{c}}(\mathrm{x})=(\mathrm{C}(\neg$ $\mathrm{x}))^{\mathrm{c}}$ for all $\mathrm{x} C \neg \mathrm{A}$ and $\mathrm{C}(\mathrm{U})$ is complex fuzzy power set.

Remark 3.3: [6] From now on, Let $(\mathrm{C}, \mathrm{A})$ be a non-null complex fuzzy soft set over a hypergroup $<\left(H, E^{2}\right) ; \diamond>, \mathrm{E}$ be a set of parameters and $\mathrm{A} \subseteq \mathrm{E}$, Consider $a \in \operatorname{supp}(C, A)$, $\left(w, E^{2}\right),\left(x, E^{2}\right),\left(y, E^{2}\right),\left(z, E^{2}\right) \in\left(H, E^{2}\right)$, then we can assume the complex membership function as, $C_{a}(w)=r_{a}(w) e^{i \omega_{a}(w)}, C_{a}(x)=r_{a}(x) e^{i \omega_{a}(x)}, C_{a}(y)=r_{a}(y) e^{i \omega_{a}(y)}, C_{a}(z)=r_{a}(z) e^{i \omega_{a}(z)}$.

Definition 3.4: Let $\left(C_{1}, A\right)$ and $\left(C_{2}, B\right)$ be complex fuzzy soft sets over $\mathrm{U}$. Then $\left(C_{1}, A\right)$ is called a complex fuzzy soft subset of $\left(C_{2}, B\right)$ if

(i) $A \subseteq B$,

(ii) $r_{C_{1 a}}(x) \leq r_{C_{2 a}}(x)$ and $\omega_{C_{1 a}}(x) \leq \omega_{C_{2 a}}(x)$ for every $a \in A$ and $x \in U$,

$r_{C_{1 a}}(x), r_{C_{2 a}}(x), \omega_{C_{1 a}}(x), \omega_{C_{2 a}}(x)$ are elements of $\left(C_{1}, A\right)$ and $\left(C_{2}, B\right)$ respectively. This relationship is denoted by $\left(C_{1}, A\right) \subseteq\left(C_{2}, B\right)$.

Definition 3.5: For a complex fuzzy soft set $(\mathrm{C}, \mathrm{A})$, the set $\operatorname{Supp}(\mathrm{C}, \mathrm{A})=\left\{(x \in A): r_{x} e^{i \omega_{x}} \neq \phi\right\}$ is called the support of the complex fuzzy soft set (C,A). Thus a non-null complex fuzzy soft set is a complex fuzzy soft set with an empty support and a complex fuzzy soft set $(\mathrm{C}, \mathrm{A})$ is said to be non-null if $\operatorname{Supp}(C, A) \neq \phi$

Definition 3.6: Let $(\mathrm{C}, \mathrm{A})$ be a non-null complex fuzzy soft set over $\left\langle\left(H, E^{2}\right) ; \diamond\right\rangle$. Then $(\mathrm{C}, \mathrm{A})$ is called a complex fuzzy soft quasihypergroup over $\left\langle\left(H, E^{2}\right) ; \diamond\right\rangle$ if for all $a \in \operatorname{supp}(C, A)$, the following conditions are satisfied:

(i) For all $\left(w, E^{2}\right),\left(x, E^{2}\right) \in\left(H, E^{2}\right)$ there exists a $\left(y, E^{2}\right) \in\left(H, E^{2}\right)$ such that $\left(x, E^{2}\right) \in\left(w, E^{2}\right) \diamond\left(y, E^{2}\right)$ and $\min \left(r_{a}(w), r_{a}(x)\right) \leq r_{a}(y), \min \left(\omega_{a}(w), \omega_{a}(x)\right) \leq \omega_{a}(y)$

(ii) For all $\left(w, E^{2}\right),\left(x, E^{2}\right) \in\left(H, E^{2}\right)$ there exists a $\left(z, E^{2}\right) \in\left(H, E^{2}\right)$ such that $\left(x, E^{2}\right) \in\left(z, E^{2}\right) \oslash\left(w, E^{2}\right)$ and $\min \left(r_{a}(w), r_{a}(x)\right) \leq r_{a}(z), \quad \min \left(\omega_{a}(w), \omega_{a}(x)\right) \leq \omega_{a}(z)$

Definition 3.7: Let $(\mathrm{C}, \mathrm{A})$ be a non-null complex fuzzy soft set over $\left\langle\left(H, E^{2}\right) ; \diamond\right\rangle$. Then $(\mathrm{C}, \mathrm{A})$ is called a complex fuzzy soft semihypergroup over $\left\langle\left(H, E^{2}\right) ; \diamond\right\rangle$ if for all $a \in \operatorname{supp}(C, A)$ and

$$
\begin{aligned}
& \left(x, E^{2}\right),\left(y, E^{2}\right) \in\left(H, E^{2}\right) \min \left(r_{a}(x), r_{a}(y)\right) \leq \inf \left\{r_{a}(z):\left(z, E^{2}\right) \in\left(x, E^{2}\right) \diamond\left(y, E^{2}\right)\right\}, \\
& \min \left(\omega_{a}(x), \omega_{a}(y)\right) \leq \inf \left\{\omega_{a}(z):\left(z, E^{2}\right) \in\left(x, E^{2}\right) \oslash\left(y, E^{2}\right)\right\} .
\end{aligned}
$$

Definition 3.8: Let $(\mathrm{C}, \mathrm{A})$ be a non-null complex fuzzy soft set over a hypergroup $\left\langle\left(H, E^{2}\right) ; \diamond\right\rangle$. Then (C,A) is called a complex fuzzy soft hypergroup over $\left\langle\left(H, E^{2}\right) ; \diamond\right\rangle$ if for all $a \in \operatorname{supp}(C, A)$, the following conditions are satisfied:

(i) For all $\left(x, E^{2}\right),\left(y, E^{2}\right) \in\left(H, E^{2}\right), \quad \min \left(r_{a}(x), r_{a}(y)\right) \leq \inf \left\{r_{a}(z):\left(z, E^{2}\right) \in\left(x, E^{2}\right) \oslash\left(y, E^{2}\right)\right\}$, 


$$
\min \left(\omega_{a}(x), \omega_{a}(y)\right) \leq \inf \left\{\omega_{a}(z):\left(z, E^{2}\right) \in\left(x, E^{2}\right) \oslash\left(y, E^{2}\right)\right\} .
$$

(ii) For all $\left(w, E^{2}\right),\left(x, E^{2}\right) \in\left(H, E^{2}\right)$, there exists a $\left(y, E^{2}\right) \in\left(H, E^{2}\right)$ such that $\left(x, E^{2}\right) \in\left(w, E^{2}\right) \diamond\left(y, E^{2}\right)$ and $\min \left(r_{a}(w), r_{a}(x)\right) \leq r_{a}(y), \quad \min \left(\omega_{a}(w), \omega_{a}(x)\right) \leq \omega_{a}(y)$

(iii) For all $\left(w, E^{2}\right),\left(x, E^{2}\right) \in\left(H, E^{2}\right)$, there exists a $\left(z, E^{2}\right) \in\left(H, E^{2}\right)$ such that $\left(x, E^{2}\right) \in\left(z, E^{2}\right) \oslash\left(w, E^{2}\right)$ and $\min \left(r_{a}(w), r_{a}(x)\right) \leq r_{a}(z), \quad \min \left(\omega_{a}(w), \omega_{a}(x)\right) \leq \omega_{a}(z)$

That is, $\mathrm{C}_{\mathrm{a}}$ (from Remark) is non-null complex fuzzy subhypergroup of $\left\langle\left(H, E^{2}\right) ; \diamond\right\rangle$ for all $a \in \operatorname{supp}(C, A)$

Definition 3.9: Let $\left(C_{1}, A\right)$ and $\left(C_{2}, B\right)$ be complex fuzzy soft hypergroups over $<\left(H, E^{2}\right) ; \diamond>$. Then $\left(C_{1}, A\right)$ is called a complex fuzzy soft subhypergroup of $\left(C_{2}, B\right)$, which is denoted as $\left(C_{1}, A\right) \leq_{s}\left(C_{2}, B\right)$ if the following conditions are satisfied:

(i) $A \subseteq B$,

(ii) $C_{1 a}$ is a non-null complex fuzzy subhypergroup of $C_{2 a}$ for all $a \in \operatorname{supp}\left(C_{1}, A\right)$

Theorem 3.10: Let $\left(C_{1}, A\right)$ and $\left(C_{2}, B\right)$ be complex fuzzy soft hypergroups over $<\left(H, E^{2}\right) ; \diamond>$ and $\left(C_{1}, A\right)$ be a complex fuzzy soft subset of $\left(C_{2}, B\right)$. Then $\left(C_{1}, A\right) \leq_{s}\left(C_{2}, B\right)$

Proof. Let $\left(C_{1}, A\right)$ and $\left(C_{2}, B\right)$ be complex fuzzy soft hypergroups over $<\left(H, E^{2}\right) ; \diamond>$ and $\left(C_{1}, A\right)$ be a complex fuzzy soft subset of $\left(C_{2}, B\right)$, i.e. $\left(C_{1}, A\right) \subseteq\left(C_{2}, B\right)$. Since $\left(C_{1}, A\right) \subseteq\left(C_{2}, B\right)$, by Definition 4.6, it can be concluded that $A \subseteq B$, and also, since $\left(C_{1}, A\right)$ and $\left(C_{2}, B\right)$ are complex fuzzy soft hypergroups over $<\left(H, E^{2}\right) ; \diamond>$ and $\left(C_{1}, A\right) \subseteq\left(C_{2}, B\right), C_{1 a}$ is a non-null complex fuzzy subhypergroup of $C_{2 a}$ for all $a \in \operatorname{supp}\left(C_{1}, A\right)$.As such, $\left(C_{1}, A\right)$ is a complex fuzzy soft hypergroup over $\left(C_{2}, B\right)$. Hence $\left(C_{1}, A\right)$ is a complex fuzzy soft subhypergroup of $\left(C_{2}, B\right)$. i.e, $\left(C_{1}, A\right) \leq_{s}\left(C_{2}, B\right)$

Definition 3.11: Let $(\mathrm{C}, \mathrm{A})$ be a non-null complex fuzzy soft set over $\left\langle\left(R, E^{2}\right),+, \diamond\right\rangle$. Then $(\mathrm{C}, \mathrm{A})$ is called a complex fuzzy soft hyperring (from the definition of fuzzy soft hyperring [4],[6]) over $\mathrm{R}$ if for all $a \in \operatorname{Supp}(C, A)$, the following conditions are satisfied:

(a) $\left(x, E^{2}\right),\left(y, E^{2}\right) \in\left(R, E^{2}\right)$

$$
\begin{aligned}
& \min \left(r_{a}(x), r_{a}(y)\right) \leq \inf \left\{r_{a}(z):\left(z, E^{2}\right) \in\left(x, E^{2}\right)+\left(y, E^{2}\right)\right\}, \\
& \min \left(\omega_{a}(x), \omega_{a}(y)\right) \leq \inf \left\{\omega_{a}(z):\left(z, E^{2}\right) \in\left(x, E^{2}\right)+\left(y, E^{2}\right)\right\} .
\end{aligned}
$$

(b) For all $\left(w, E^{2}\right),\left(x, E^{2}\right) \in\left(R, E^{2}\right)$, there exists a $\left(y, E^{2}\right) \in\left(R, E^{2}\right)$ such that

$$
\begin{aligned}
& \left(x, E^{2}\right) \in\left(w, E^{2}\right)+\left(y, E^{2}\right) \text { and } \min \left(r_{a}(w), r_{a}(x)\right) \leq r_{a}(y), \\
& \min \left(\omega_{a}(w), \omega_{a}(x)\right) \leq \omega_{a}(y),
\end{aligned}
$$

(c) For all $\left(w, E^{2}\right),\left(x, E^{2}\right) \in\left(R, E^{2}\right)$, there exists a $\left(z, E^{2}\right) \in\left(R, E^{2}\right)$ such that 


$$
\begin{aligned}
& \left(x, E^{2}\right) \in\left(z, E^{2}\right)+\left(w, E^{2}\right) \text { and } \min \left(r_{a}(w), r_{a}(x)\right) \leq r_{a}(z), \\
& \min \left(\omega_{a}(w), \omega_{a}(x)\right) \leq \omega_{a}(z), \\
& \text { (d) For all }\left(x, E^{2}\right),\left(y, E^{2}\right) \in\left(R, E^{2}\right), \\
& \quad \min \left(r_{a}(x), r_{a}(y)\right) \leq \inf \left\{r_{a}(z):\left(z, E^{2}\right) \in\left(x, E^{2}\right) \oslash\left(y, E^{2}\right)\right\}, \\
& \min \left(\omega_{a}(x), \omega_{a}(y)\right) \leq \inf \left\{\omega_{a}(z):\left(z, E^{2}\right) \in\left(x, E^{2}\right) \diamond\left(y, E^{2}\right)\right\} .
\end{aligned}
$$

That is $\mathrm{C}_{\mathrm{a}}$ (from Remark 3.5.) is a non-null complex fuzzy subhyperring of $\mathrm{R}$ for each $a \in \operatorname{supp}(C, A)$.

Theorem 3.12: Let (C,A) be a complex fuzzy softest over $\left\langle\left(R, E^{2}\right),+, \diamond>\right.$. Then $(C, A)$ is a complex fuzzy soft hyperring over $\left\langle\left(R, E^{2}\right),+, \diamond\right\rangle$ if and only if for every $|t| \in[0,1],(C, A)_{t}$ is a complex soft hyperring over R.

Proof. $\quad(\Rightarrow)$ Since $\mathrm{R}$ is a hyperring, $<\left(R, E^{2}\right),+>$ is a commutative hypergroup and $<\left(R, E^{2}\right), \diamond>$ is a semihypergroup. Let $(C, A)$ be a complex fuzzy soft hyperring over $<\left(R, E^{2}\right),+, \diamond>$ and $|t| \in[0,1]$. Then for all $a \in \operatorname{supp}(C, A)$, the corresponding $\mathrm{C}_{\mathrm{a}}$ is a complex fuzzy subhyperring of R.

Now let $\left(x, E^{2}\right),\left(y, E^{2}\right) \in\left(C_{a}\right)_{t}$, Then $r_{a}(x) \geq|t|, \omega_{a}(x) \geq|t|$ and $r_{a}(y) \geq|t|, \omega_{a}(y) \geq|t|$, Furthermore since $C_{a}$ is a complex fuzzy subhypergroup of $\left\langle\left(R, E^{2}\right),+>\right.$, we have $\inf \left\{r_{a}(z):\left(z, E^{2}\right) \in\left(x, E^{2}\right)+\left(y, E^{2}\right)\right\} \geq \min \left(r_{a}(x), r_{a}(y)\right) \geq|t|$ and $\inf \left\{\omega_{a}(z):\left(z, E^{2}\right) \in\left(x, E^{2}\right)+\left(y, E^{2}\right)\right\} \geq \min \left(\omega_{a}(x), \omega_{a}(y)\right) \geq|t| . \quad$ This $\quad$ implies that $\left(z, E^{2}\right) \in\left(C_{a}\right)_{t}$,

and therefore for every $\left(z, E^{2}\right) \in\left(x, E^{2}\right)+\left(y, E^{2}\right)$, we obtain $\left(x, E^{2}\right)+\left(y, E^{2}\right) \subseteq\left(C_{a}\right)_{t}$, then $r_{a}(x) \geq|t|, \omega_{a}(x) \geq|t|$ and $r_{a}(z) \geq|t|, \omega_{a}(z) \geq|t|$. Due to the fact that $C_{a}$ is a complex fuzzy subhypergroup of $<\left(R, E^{2}\right),+>$, there exists $\left(y, E^{2}\right) \in<\left(R, E^{2}\right),+, \diamond>$ such that $\left(x, E^{2}\right) \in\left(z, E^{2}\right)+\left(y, E^{2}\right)$ and $\min \left(r_{a}(z), r_{a}(x)\right) \leq r_{a}(y)$ and $\min \left(\omega_{a}(z), \omega_{a}(x)\right) \leq \omega_{a}(y)$. Since $\left(x, E^{2}\right),\left(z, E^{2}\right) \in\left(C_{a}\right)_{t}$. Then $r_{a}(x) \geq|t|, \omega_{a}(x) \geq|t|$ and $r_{a}(z) \geq|t|, \omega_{a}(z) \geq|t|$ and this implies that $r_{a}(y) \geq|t|, \omega_{a}(y) \geq|t|$ and as a result, $\left(y, E^{2}\right) \in\left(C_{a}\right)_{t}$. Therefore, we obtain $\left(C_{a}\right)_{t} \subseteq\left(z, E^{2}\right)+\left(C_{a}\right)_{t}$

As such, we obtain $\left(z, E^{2}\right)+\left(C_{a}\right)_{t}=\left(C_{a}\right)_{t}$. As a result, $\left(C_{a}\right)_{t}$ is a complex subhypergroup of $<\left(R, E^{2}\right),+>$. Hence $(C, A)_{t}$ is a soft hypergroup over $<\left(R, E^{2}\right),+>$. Furthermore, Since $<\left(R, E^{2}\right), \diamond>$ is a semihypergroup, $C_{a}$ is a non-null complex fuzzy subsemihypergroup of $<\left(R, E^{2}\right), \diamond>$ for all $a \in \operatorname{supp}(C, A)$ and $\min \left(r_{a}(x), r_{a}(y)\right) \leq \inf \left\{r_{a}(z):\left(z, E^{2}\right) \in\left(x, E^{2}\right) \diamond\left(y, E^{2}\right)\right\}$, $\min \left(\omega_{a}(x), \omega_{a}(y)\right) \leq \inf \left\{\omega_{a}(z):\left(z, E^{2}\right) \in\left(x, E^{2}\right) \oslash\left(y, E^{2}\right)\right\}$. Now let $\left(x, E^{2}\right),\left(y, E^{2}\right) \in\left(C_{a}\right)_{t}$. Then 
$r_{a}(x) \geq|t|, \omega_{a}(x) \geq|t|$ and $r_{a}(y) \geq|t|, \omega_{a}(y) \geq|t|$. Therefore it follows that $\min \left(r_{a}(x), r_{a}(y)\right) \geq|t|$, $\min \left(\omega_{a}(x), \omega_{a}(y)\right) \geq|t|$ and this implies that $\inf \left\{r_{a}(z):\left(z, E^{2}\right) \in\left(x, E^{2}\right) \diamond\left(y, E^{2}\right)\right\} \geq|t|$ and $\inf \left\{\omega_{a}(z):\left(z, E^{2}\right) \in\left(x, E^{2}\right) \oslash\left(y, E^{2}\right)\right\} \geq|t|$.This in turn implies that $\left(z, E^{2}\right) \in\left(C_{a}\right)_{t}$ and consequently $\left(x, E^{2}\right) \diamond\left(y, E^{2}\right) \subseteq\left(C_{a}\right)_{t}$. Therefore for every $\left(x, E^{2}\right),\left(y, E^{2}\right) \in\left(C_{a}\right)_{t}$, we obtain $\left(x, E^{2}\right) \diamond\left(y, E^{2}\right) \in P^{*}(R), P^{*}(R)$ is the set of all non-empty subsets of $\left\langle\left(R, E^{2}\right),+, \diamond>\right.$. As such, $\left(C_{a}\right)_{t}$ is a subhyperring of $\left\langle\left(R, E^{2}\right),+, \diamond\right\rangle$. Hence $(C, A)_{t}$ is a soft hyperring over $<\left(R, E^{2}\right),+, \diamond>$.

$(\Rightarrow)$ Assume that $(C, A)_{t}$ is a complex soft hyperring over $\left\langle\left(R, E^{2}\right),+, \diamond\right\rangle$. Thus for every $|t| \in[0,1], \quad\left(C_{a}\right)_{t} \quad$ is a non-null subhyperring of $\left\langle\left(R, E^{2}\right),+, \diamond\right\rangle$. Now for every $\left(x, E^{2}\right),\left(y, E^{2}\right) \in<\left(R, E^{2}\right),+, \diamond>$, we have $\min \left(r_{a}(x), r_{a}(y)\right) \leq r_{a}(x) ; \min \left(\omega_{a}(x), \omega_{a}(y)\right) \leq \omega_{a}(x)$ or $\min \left(r_{a}(x), r_{a}(y)\right) \leq r_{a}(y) ; \min \left(\omega_{a}(x), \omega_{a}(y)\right) \leq \omega_{a}(y)$. So if we let $\min \left(r_{a}(x), r_{a}(y)\right)=\left|t_{0}\right|$; $\min \left(\omega_{a}(x), \omega_{a}(y)\right)=\left|t_{0}\right|$, then $\left(x, E^{2}\right),\left(y, E^{2}\right) \in\left(C_{a}\right)_{t_{0}}$ and therefore $\left(x, E^{2}\right)+\left(y, E^{2}\right) \subseteq\left(C_{a}\right)_{t_{0}}$, Therefore for every $\left(z, E^{2}\right) \in\left(x, E^{2}\right)+\left(y, E^{2}\right)$, we have $C_{a}(z) \geq\left|t_{0}\right|$ which implies that $\min \left(r_{a}(x), r_{a}(y)\right) \leq \inf \left\{r_{a}(z):\left(z, E^{2}\right) \in\left(x, E^{2}\right)+\left(y, E^{2}\right)\right\}$ and $\quad \min \left(\omega_{a}(x), \omega_{a}(y)\right) \leq$ $\inf \left\{\omega_{a}(z):\left(z, E^{2}\right) \in\left(x, E^{2}\right)+\left(y, E^{2}\right)\right\}$. As such, condition (a) of Definition 3.12 is verified. Next, let $\left(w, E^{2}\right),\left(x, E^{2}\right) \in<\left(R, E^{2}\right),+, \diamond>$ and $\min \left(r_{a}(w), r_{a}(x)\right)=\left|t_{1}\right| ; \min \left(\omega_{a}(w), \omega_{a}(x)\right)=\left|t_{1}\right|$, this implies that $\left(w, E^{2}\right),\left(x, E^{2}\right) \in\left(C_{a}\right)_{t_{1}}$ which means that there exists $\left(y, E^{2}\right) \in\left(C_{a}\right)_{t_{1}}$ such that $\left(x, E^{2}\right) \in\left(w, E^{2}\right) \oslash\left(y, E^{2}\right)$. Since $\left(y, E^{2}\right) \in\left(C_{a}\right)_{t_{1}}$, we have $C_{a}(z) \geq\left|t_{1}\right|$ and thus $\min \left(r_{a}(w), r_{a}(x)\right)$ $\leq r_{a}(y) ; \min \left(\omega_{a}(w), \omega_{a}(x)\right) \leq \omega_{a}(y)$. Therefore condition(b) of Definition 3.12 has been verified. Condition (c) of Definition 3.12 can be verified in a similar manner. Thus it has been proven that $C_{a}$ is a complex fuzzy subhypergroup of $\left\langle\left(R, E^{2}\right),+>\right.$. Now $\left(C_{a}\right)_{t}$ is a sub semihypergroup of the semihypergroup $\quad<\left(R, E^{2}\right), \diamond>$. Let $\min \left(r_{a}(x), r_{a}(y)\right)=\left|t_{2}\right|$ for $\operatorname{every}\left(x, E^{2}\right),\left(y, E^{2}\right) \in$ $<\left(R, E^{2}\right),+, \diamond>$. Thus $\left(x, E^{2}\right),\left(y, E^{2}\right) \in\left(C_{a}\right)_{t_{2}}$ and therefore we have $\left(x, E^{2}\right) \oslash\left(y, E^{2}\right) \subseteq\left(C_{a}\right)_{t_{2}}$. Thus for every $\left(z, E^{2}\right) \in\left(x, E^{2}\right) \oslash\left(y, E^{2}\right)$, we obtain $C_{a}(z) \geq\left|t_{2}\right|$. As a result, we obtain $\min \left(r_{a}(x), r_{a}(y)\right) \leq \inf \left\{r_{a}(z):\left(z, E^{2}\right) \in\left(x, E^{2}\right) \diamond\left(y, E^{2}\right)\right\}$ and $\quad \min \left(r_{a}(x), r_{a}(y)\right) \leq \inf \left\{\left(\omega_{a}(z):\right.\right.$ $\left.\left(z, E^{2}\right) \in\left(x, E^{2}\right) \diamond\left(y, E^{2}\right)\right\}$. Which proves that condition(d) of Definition 3.12 has been verified. As such, $C_{a}$ is a complex fuzzy subhyperring of $\left\langle\left(R, E^{2}\right),+, \diamond\right\rangle$. Hence it has been proven that $(C, A)$ is a complex fuzzy soft hyperring over $\left\langle\left(R, E^{2}\right),+, \diamond\right\rangle$.

\section{CONCLUSION}

This paper presented a new concept of complex fuzzy soft hypergroup, which is derived from the innovative concept of a complex fuzzy hypergroup on complex fuzzy spaces 


\section{REFERENCES}

[1] Abdallah Al-Husban, Abdul Razak Salleh, "Complex Fuzzy Hypergroups Based on Complex Fuzzy Spaces”, International Journal of Pure and Applied Mathmatics, Vol.107, No.4, (2016), pp. 949-958.

[2] N.Cagman, Filiz Citak, Serdar Enginoglu, "FP-Soft set Theory and its Applications", Annals of Fuzzy Mathematics and Informatics, Vol. 2, No. 2, (2011), pp. 219-226

[3] N. Cagman, S. Enginoglu and F. Citak, "Fuzzy Soft Set Theory and Its Applications", Iranian Journal of Fuzzy Systems, Vol.8, No.3, (2011), pp. 137-147.

[4] Ganeshsree Selvachandran, "Fuzzy Soft Hyperrings and Fuzzy Soft Hyperideals" , Global Journal of Pure and Applied Mathematics, Vol. 11, No. 2 (2015), pp. 807-823.

[5] Ganeshsree Selvachandran, Abdul Razak Salleh, "Hypergroup Theory Applied to Fuzzy Soft Sets”, Global Journal of Pure and Applied Mathematics, Vol. 11, No. 2 (2015), pp. 825-835.

[6] Ganeshsree Selvachandran, "Introduction to the theory of soft hyperrings and soft hyperring homomorphism", JP Journal of Algebra, Number theory and Applications, Vol. 36, No. 3 (2015), pp. 279 - 294.

[7] Guangquan Zhang, Tharam Singh Dillon, Kai-Yuan Cai, Jun Ma and Jie Lu, "Operation Properties and $\delta$-Equalities of Complex Fuzzy Sets", Fuzzy sets and Fuzzy Systems.

[8] A.M. Ibrahim A.M , A.O. yusuf, "Development of Soft Set Theory", American International Journal of Contemporary Research, Vol.2, No. 9,(2012); pp. 205 - 210

[9] Khaleed Alhazaymeh, Shafida Abdul Halim, Abdul Razak Salleh and Nasruddin Hassan, "Soft IFS", Applied Mathematical Sciences, Vol.6, No. 54(2012), pp. 2669 - 2880

[10] D. A. Molodtsov. Soft set theory - First result, Computers Math. Appl. 37 (4/5) 19-3, 1999.

[11] D. Ramot, R. Milo, M. Friedman, and A. Kandel, "Complex fuzzy sets" IEEE Trans. Fuzzy Syst., vol. 10, No. 2, pp. 171-186, Apr.2002.

[12] D. Ramot, M. Friedman, G. Langholz, and A. Kandel, “Complex fuzzy logic," IEEE Trans. Fuzzy Syst., vol. 11, no. 4, pp. 450-461, Aug. 2003.

[13] Thirunavukarasu, P., Suresh, R., "Soft Complex Fuzzy Sets", IMRF Journal, Vol: 3, Issue: 1, pp. 72-76, 2014.

[14] L. A. Zadeh," Fuzzy Sets”, Inform. And Control 8 (1965), pp. $338-353$. 